\title{
PRESERVING THE NATURAL LANDSCAPE ON THE CONSTRUCTION SITE FOR SUSTAINABLE ECOSYSTEM
}

\author{
Nikolay Sokolov ${ }^{1 *}$ Sergey Ezhov ${ }^{1}$ Svetlana Ezhova ${ }^{2}$ \\ ${ }^{1}$ Chuvash State defense University named after I.N. Ulyanov \\ ${ }^{2}$ Volga State Technological University, Russia
}

\begin{abstract}
Development and extension of urban infrastructure increasingly frequently involves the areas with compound relief forms. From the environmental point of view it is vitally important to preserve the unique landscapes for future generations. Innovative approaches meant to stabilize and reinforce ground on the building construction sites, particularly on slopes, solve the defined engineering problem. The paper addresses a case study of geotechnical design and construction practice in the complex conditions.
\end{abstract}

Key words: Ecology of capital construction, Conservation of landscape, Slope stability, Stabilization of geomorphological processes, Constrained environment, Drilling injection pile for electric-discharge technology

\section{INTRODUCTION}

As a result of geomorphological processes the ground surface developed unique landscapes. Landscape is a genetically homogeneous territorial complex with representative conditions [01]. In the $21^{\text {st }}$ century it is important to preserve the natural landscape by adjusting the buildings and constructions to the established landscape scene, non-destructively towards the existing harmony and ecology, thus, supporting the current ecosystem.

The contemporary urbanized processes increasingly frequently embrace the areas, which are not quite suitable for the capital construction. Slope development requires a particular approach ensuring soil stability. The core concern in such geotechnical case is the landslide control planning and implementation aimed at stabilizing the unique natural relief.

Nizhny Novgorod is located on the adjacent banks of the Volga River with a typical river valley relief, significant elevation differences and complex hydrology. The situation on building sites is complicated by the presence of various underground utility systems, which make the solution of the engineering tasks of relief reinforcement more difficult and enhance the necessity of slope stabilization and further landslide control.

Drilling injection piles (electric-discharge technology EDT -piles) (RU 2318961 C2, RU 2318960 C2, RU 2250958 C2, RU 2250959 C2, RU 2282936 C1) and ground anchorages (electric-discharge technology EDT -anchorages) (RU 161650 U1, RU 2605213 C1) [02-17] produced based on electric-discharge technology (EDT) were used as the construction elements ensuring slope stability when constructing a municipal building in Nizhny Novgorod.

The technological consequence of EDT pile and EDT anchorages installation (Figure 1) represents a number of stages: 1 . Well drilling (Stage 1); 2 . Well fill-up with fine concrete (stage 2); 3 . Electrohydraulic processing of the wellbore (stage 3); 4. Definition of absolute elevations of the possible enlargements along the well based on elecro-hydraulic processing results (Stages 4-5); 5. Reinforcing of the well filled in with fine concrete by eletro-hydraulic installation of reinforcement cage (Stage $6)$.

Particular attention should be paid to Stage 4. Electrohydraulic processing of the pile shaft filled with fine concrete is examined for the loose ground layer (Stage 3). Absolute elevations of loose ground are entered into a site diary. It is worthwhile keeping in mind that a loose ground layer (particularly for EDT technology) is characterised by increased values of fine concrete subsidence observed visually or using geodetic instruments. As a rule the enlargements are established on the elevations with the increased values of concrete subsidence. Electro-hydraulic processing on these elevations is carried out until the zero values of subsidence are obtained (Stage 5). The enlargement sizes (the volume measured in cubic meters and the radius, measured in metres) can be defined using formula 4 [02]. The final stage (Stage 6) involves reinforcing of the well of eletro-hydraulic installation with a reinforcement cage.

As a result of the patented innovative electric discharge processing there are additional roughness and extensions formed on the sidewall of a pile and the anchorage. Due to the enlargements (Figure 1) the carrying capacity of a pile increases significantly due to the increase of the contact surface between a pile and the ground. As a result the anchorage provides a better and more reliable support than an ordinary pile of the same length.

In terms of its geomorphology the construction site is located on the high right bank of the Volga River (Figure 2). The surface of the construction site is uneven. The surface continuous gradient is to the North. The elevations of the surface vary from 140 to $148 \mathrm{~m}$. The slope height on the site is $79-80 \mathrm{~m}$. Accessibility to the shafts are hindered. 


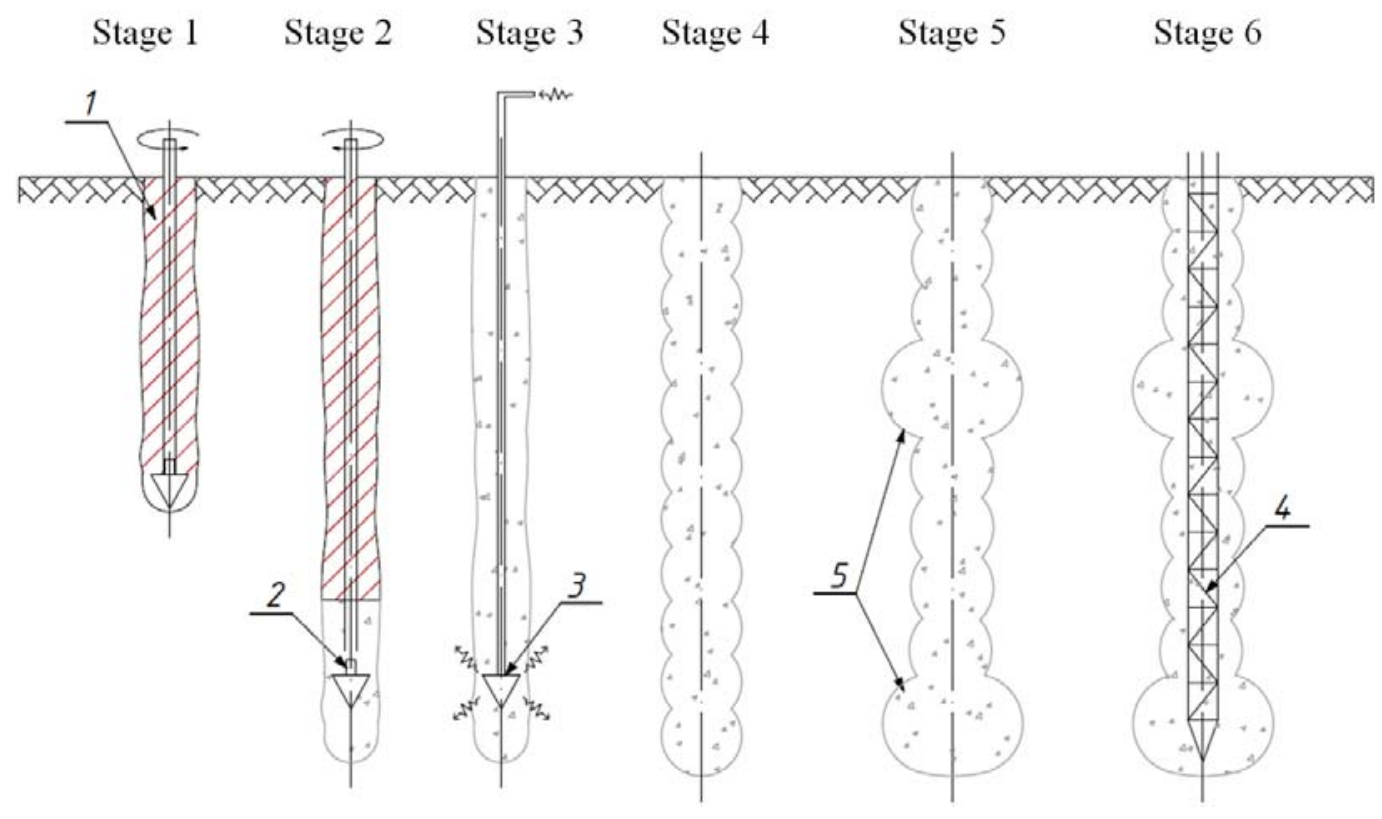

Figure 1: Technological structure system of EDT-piles

Stages 1 and 2 -design of piles and its filling with a concrete mix. Stages 3,4,5-electric-discharge processing of a wellbore wall and the bottom, Stage 6 - subsidence of the reinforcement cage

Designating symbols: 1 - flight auger, 2 - auger valve, 3 - electric emitter, 4 - spatial reinforced cage, 5 - enlargements (bearings)

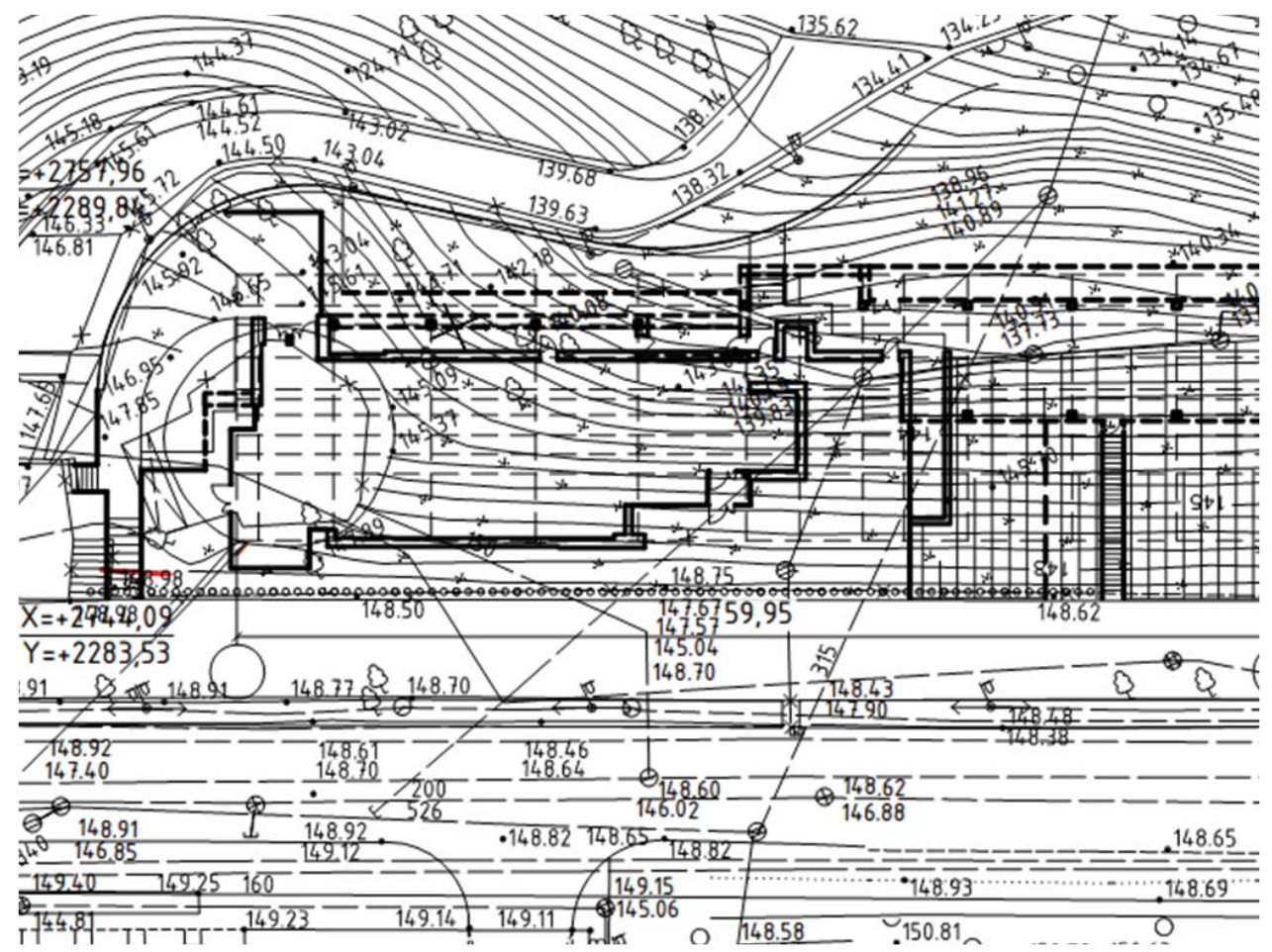

Figure 2: Site plan of the construction project 
There are underground utility systems going across the site (storm water sewage and drainage system).

The geological structure of the site to a depth of 20-60 m. (Figure 3) is represented by Middle Quaternary diluvial and soliflual formations - loess soils sediments of the Middle Permian - clays with interbedded marls and aleuritic, pulverescent and fine polymictic sands. The sediments are topped off with contemporary formations- fill up ground, represented by fine quartz sand, loam with crushed bricks, stones and construction waste amounting to $10-30 \%$. In the pile wells No 6 and No 7 the fill-up ground is represented by break stone and slack with inclusion of organic substances.

The hydrological conditions to a depth of $60 \mathrm{~m}$ (elevation mark $88.0 \mathrm{~m}$ ) are characterized by the presence of a wa-

\section{Engineering and geological section alona the line I-I}

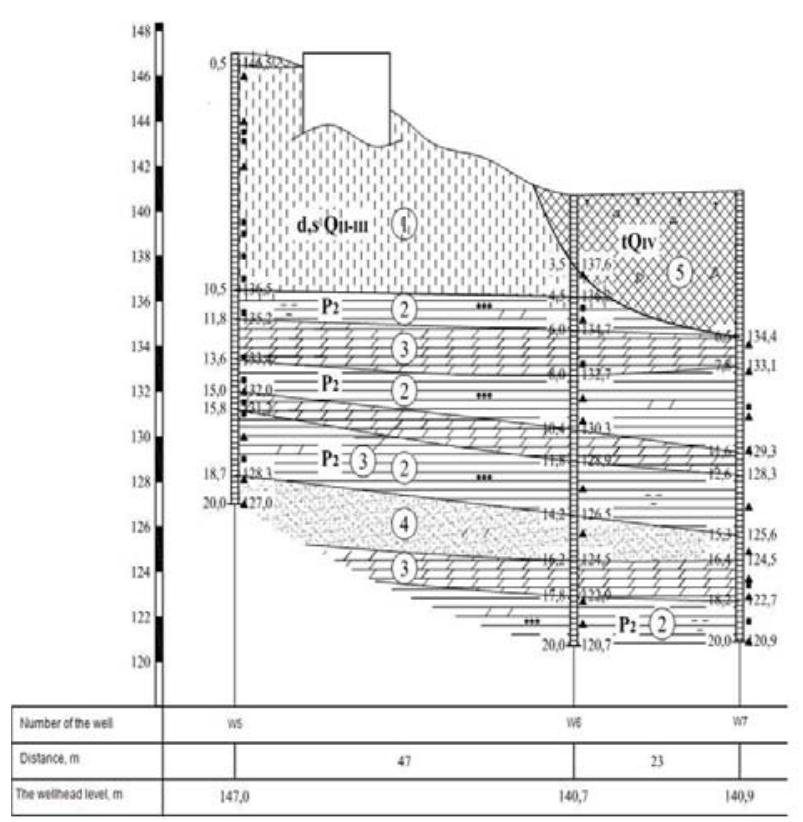

ter bearing formation dating back to Permian deposits. In the course of borehole surveying (June 2012), the water bearing formation was broached by the bore pile No 3 at a depth of 29.0. marked $101.6 \mathrm{~m}$. The established level was fixed at a depth of $28 \mathrm{~m}$. marked $102.6 \mathrm{~m}$. The horizon is with weak flow, the velocity value is $1.0 \mathrm{~m}$. Water bearing materials are represented with polymict sands as well as fractured marl and clay. Aquicude represent compact varieties and Middle Permian deposits. The horizon is recharged with atmospheric precipitations at places where the formations are coming out to the surface.

Table 1 provides performance standard and estimated ground characteristics of engineering and geological elements (for $\alpha=0.95$ ).

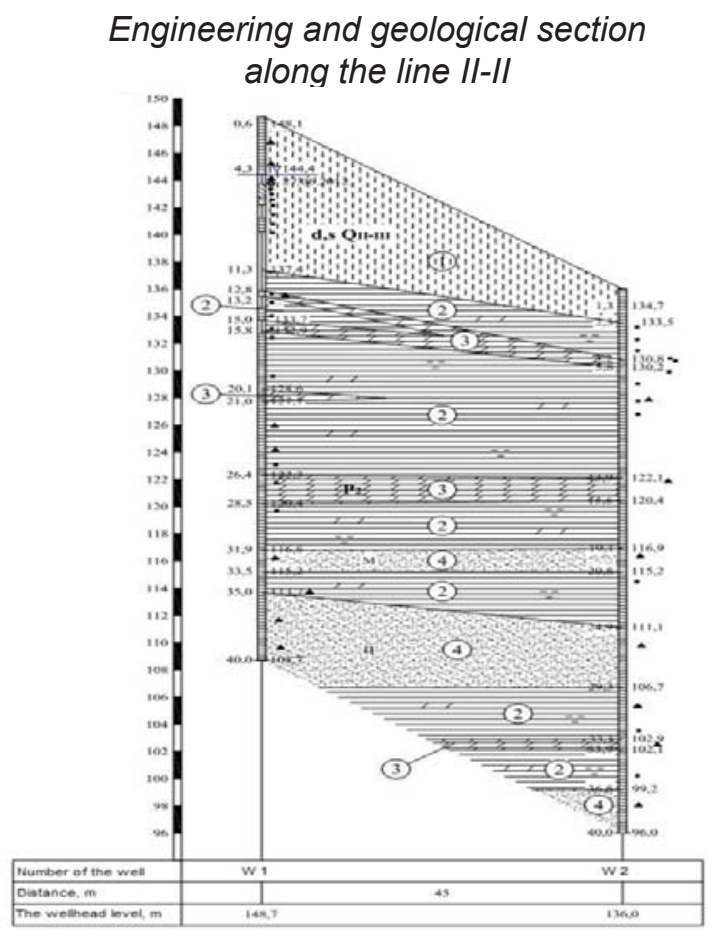

Figure 3: Engineering and geological sections

(1- loam solid; 2- solid clay; 3- marl; 4- pulverescent sand; 5- backfill soil)

Table 1

\begin{tabular}{|c|c|c|c|c|c|c|c|}
\hline \multirow{2}{*}{$\begin{array}{c}\text { No } \\
\text { EGE }\end{array}$} & \multirow{2}{*}{$\begin{array}{c}\text { Name of an engineering and geological } \\
\text { element (EGE) }\end{array}$} & \multicolumn{3}{|c|}{$\begin{array}{l}\text { Estimated characteristics, } \\
\qquad \alpha=0.85\end{array}$} & \multicolumn{3}{|c|}{$\begin{array}{l}\text { Estimated characteristics, } \\
\qquad \alpha=0.95\end{array}$} \\
\hline & & $\rho_{\|,}, \mathrm{g} / \mathrm{cm}^{3}$ & $c_{\|}, k P a$ & $\varphi_{\| \prime}$, degree & $\rho_{\rho}, \mathrm{g} / \mathrm{cm}^{3}$ & $c_{p}, \mathrm{kPa}$ & $\varphi_{1}$, degree \\
\hline 1 & $\begin{array}{l}\text { Loess loam, loam solid, semi-solid, } \\
\text { low-plastic, subsiding }\end{array}$ & 2.02 & $25 / 21$ & $15 / 14$ & 2.01 & $13 / 11$ & $14 / 13$ \\
\hline 2 & $\begin{array}{l}\text { Solid clay with marl and } \\
\text { aleurite interlayers }\end{array}$ & 1.94 & 99 & 25 & 1.93 & 95 & 24 \\
\hline 3 & $\begin{array}{l}\text { Loamy marl with clay and } \\
\text { aleurite interlayers }\end{array}$ & 1.91 & 51 & 15 & 1.89 & 27 & 7 \\
\hline 4 & $\begin{array}{l}\text { Fine, pulverescent, polymict, } \\
\text { slightly wet sand }\end{array}$ & 1.85 & 1.4 & 30 & 1.81 & 0.18 & 24 \\
\hline 5 & $\begin{array}{l}\text { Backfill soil: breakstone, } \\
\text { slack of carbonaceous rock }\end{array}$ & & & & 72 & 20 & \\
\hline
\end{tabular}


The analysis of slope stability taken together with a piling wall of drilling injection EDT-piles and EDT anchorages was carried out using GeoWall and GeoStab software. Based on the research results of the soil force (Figure 4), a piling wall was designed (Figure 5) of drilling injection EDT-piles $\varnothing 400 \mathrm{~mm}$ spaced at intervals of $700 \mathrm{~mm}$ and two layers of ground anchorage.

Construction of the anchored piling wall presumes the following operating procedure:

1. Fencing of excavation made from drilling injection piles spaced at intervals of $700 \mathrm{~mm}$ (Figure 6);

2. Ground digging for the first layer of EDT ground anchorages;

3. Installation of the EDT ground anchorages of the first layer;

4. Upon the completion of the routine break necessary for solidifying of fine concrete at the anchorage root there is a post-tensioning of EDT anchorages along the preliminarily mounted anchorage belt;

5. Ground digging for the second layer of EDT ground anchorages;

6. Installation of the EDT ground anchorages of the second layer;
7. Upon the completion of the routine break necessary for solidifying of fine concrete at the anchorage root there is a post-tensioning of EDT anchorages along the preliminarily mounted anchorage belt;

8. Ground digging up to the low foundation plate.

\section{CONCLUSION}

Accurate estimation of geological and hydrologic conditions on a construction site and the engineering analysis based on the GeoWall and GeoStab software in terms of designation of ground anchoring construction and a pile wall, which enabled to provide stability of the slope ground against landslide which is proved by the two years of exploitation of the constructed building, Thus, the use of the patented method of EDT pile and EDT anchorage installation enabled to build a capital constriction in complex conditions with minimum damage to the natural environment preserving its uniqueness. The intervention on the construction stage didn't disturb the ecology and preserved the geomorphological processes, which in its turn exerted a minimum impact on the change of ecosystem on the construction site on a high and beautiful bank of the Volga River.

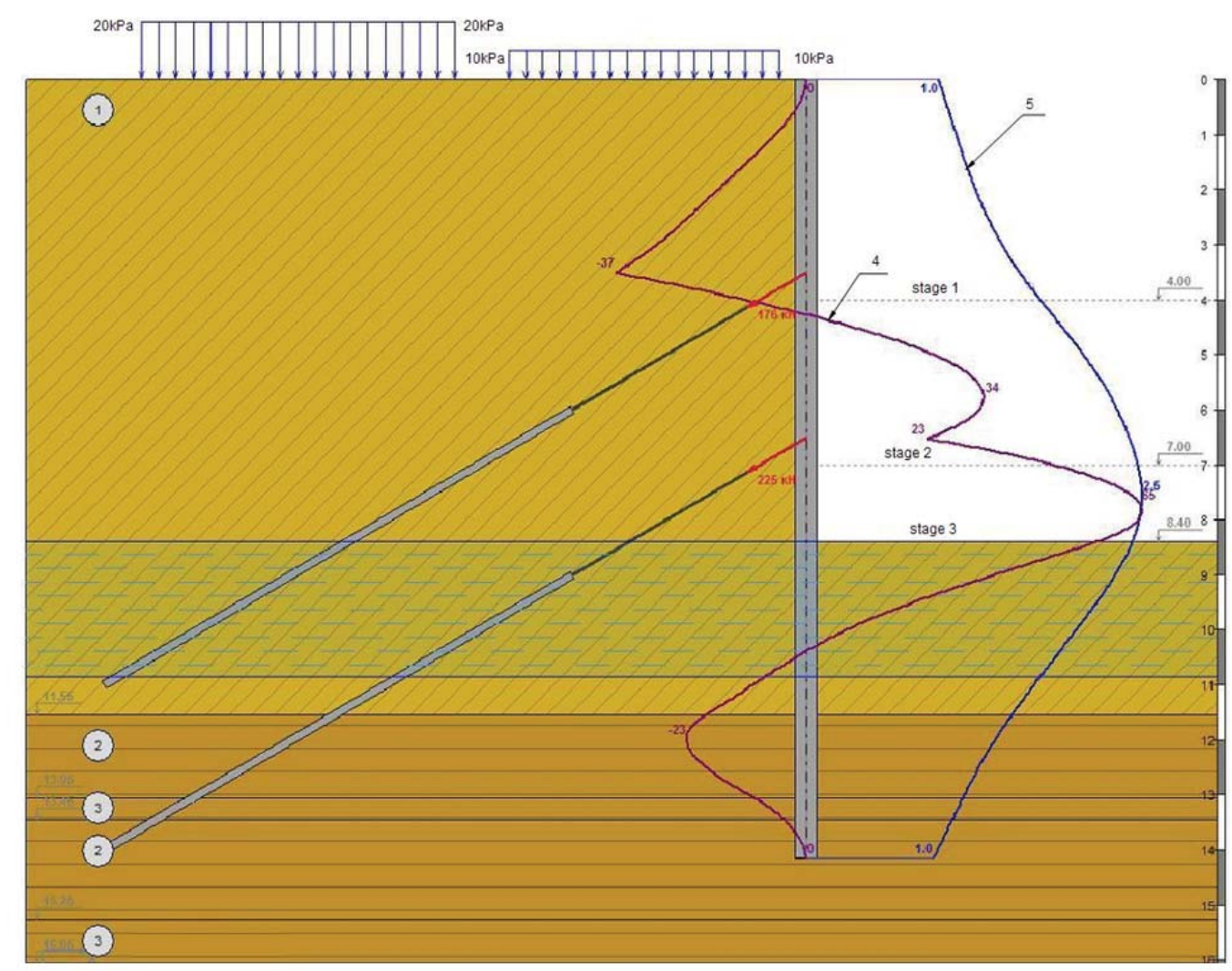

Figure 4: Displacement and bending moment diagrams

(1- loam solid; 2- solid clay; 3- marl; 4- bending moment diagram; 5- displacement diagram) 
a) Diagram layout of the ground anchorages $-E D T$ of the $1^{\text {st }}$ layer

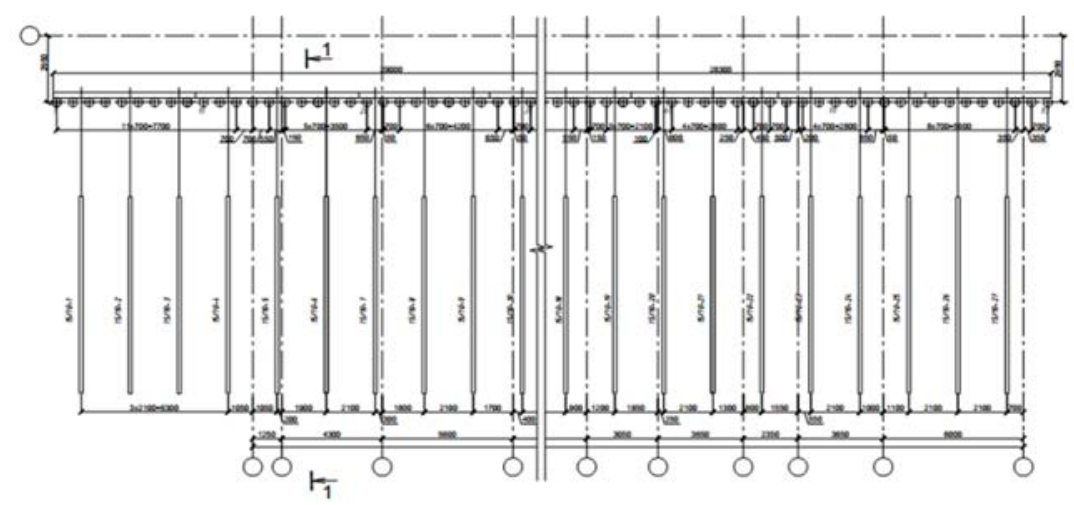

b) Diagram layout of the ground anchorages $-E D T$ of the $2^{\text {nd }}$ layer

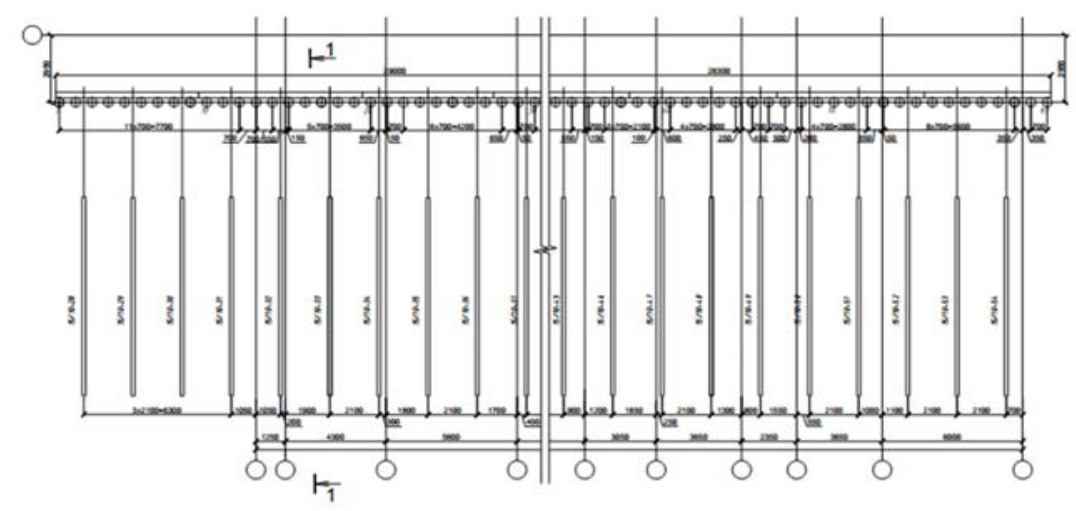

Figure 5: The scheme of the piling wall with ground anchorages

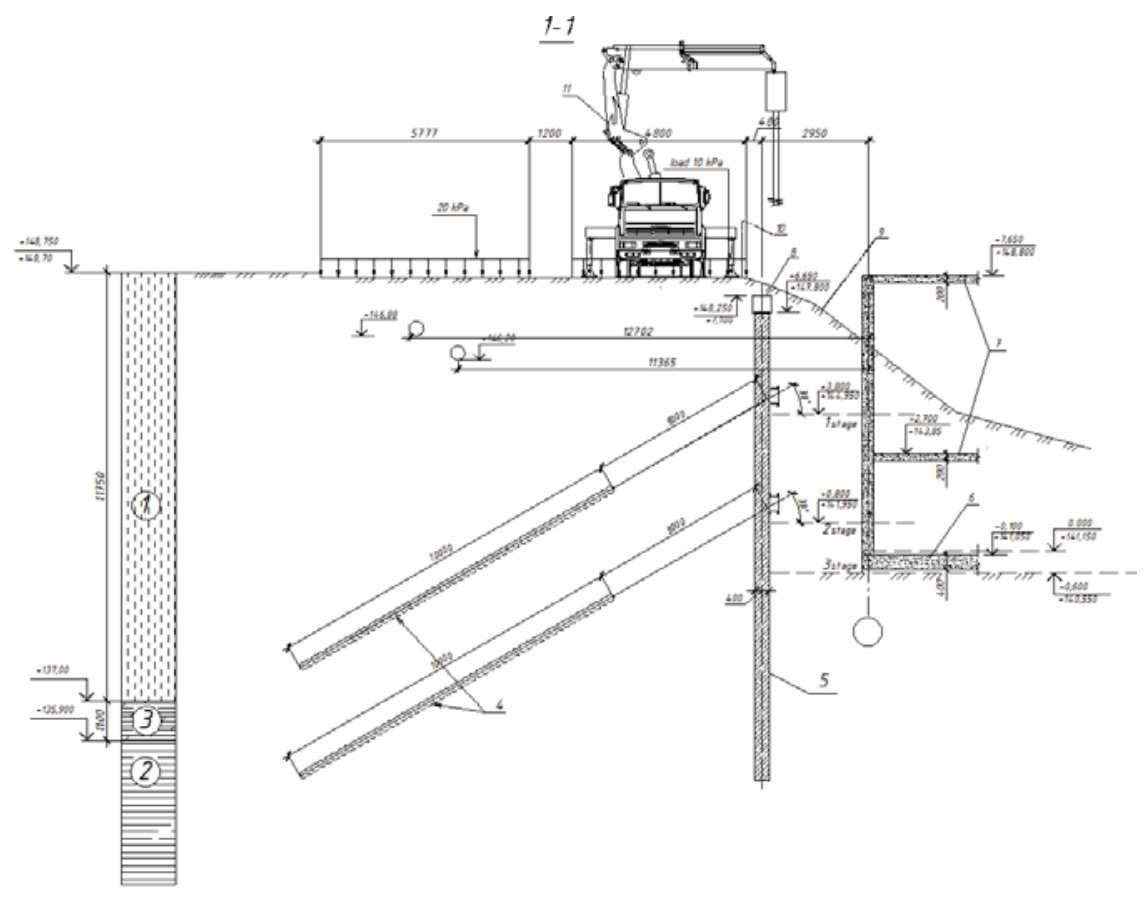

Figure 6: Section of the piling wall

(1- loam; 2- solid clay; 3- clay; 4- ground anchorages for electric discharge technology; 5- drilling injection piles for electric discharge technology; 6-foundation slab; 7- floor slabs; 8- beam; 9- ground surface; 10- railing; 11 -truck mounted crane at the stage of pile drilling) 


\section{REFERENCES}

1. Annenskaya GN, Zhuchkova VK, Konovalenko VG and etc. (1962) Morphological structure of the geographical landscape. Moscow: Lomonosow Moscow State University, pp. 56

2. Sokolov N.S., Ryabinov V.M. On the analysis method of the carrying capacity of the drilling injection piles. // "OFiMG". -2015. -No 1. PP.10-13.

3. Sokolov N.S. Determining the carrying capacity of the drilling injection piles- RIT with the developed bearings // Proceedings of the 2 All-Russian (1st International) conference "New in Architecture, Design Construction and Renovation NADCR-2012" -2012. Cheboksary: Chuvash State University Publishing House. PP.289-292.

4. Sokolov N.S., Ushkov S.M., Viktorova S.S. Experience of piled raft footing application when constructing residential buildings // Proceedings of the 2 All-Russian (1st International) conference "New in Architecture, Design Construction and Renovation NADCR-2012"-2012. Cheboksary: Chuvash State University Publishing House. PP. 293-298.

5. Sokolov N.S. Analysis method for the carrying capacity of drilling injection piles RIT with due consideration to "bearings" // Proceedings of the 2 All-Russian (1st International) conference "New in Architecture, Design Construction and Renovation NADCR-2014) -2014. Cheboksary: Chuvash State University Publishing House. PP. 407-411.

6. Sokolov N.S., Sokolov S.N., Sokolov A.N. Case study of restauration of the wrecking historical and cultural landmark of the Federal importance in Cheboksary // Proceedings of the 2 All-Russian (1st International) conference "New in Architecture, Design Construction and Renovation NADCR-2014). -2014. Cheboksary: Chuvash State University Publishing House. PP. $328-335$.

7. Sokolov N.S., Viktorova S.S., Fedorova T.G. Drilling piles with the increased carrying capacity // Proceedings of the 2 All-Russian (1st International) conference "New in Architecture, Design Construction and Renovation NADCR-2014) -2014. Cheboksary: Chuvash State University Publishing House. PP. 411-415.

8. Sokolov N.S., Petrov M.V., Ivanov V.A. The problem of drilling injection piles produced using electric discharge technology // Proceedings of the 2 All-Russian (1st International) conference "New in Architecture, Design Construction and Renovation NADCR-2014) -2014. Cheboksary: Chuvash State University Publishing House. PP. 415-420.

9. Sokolov N.S., Sokolov S.N., Sokolov A.N. Case study of restoration of the wrecking Vvedensky Cathedral in Cheboksary // Geotechnics. No 1. -2016. PP.60-65.
10. Sokolov N.S., Ryabinov V.M. On the efficiency of installing drilling injection piles with multiple enlargements using electric discharge technology // Geotechnics. -2016. No 2. PP.28-34.

11. Sokolov N.S., Ryabinov V.M. The main features and analysis of drilling injection piles with multiple enlargements // Geotechnics. No 3. -2016. PP.60-66.

12. Sokolov N.S., Ryabinov V.M. Technology of installment of drilling injection piles with the increased carrying capacity // Residential construction. No 9. -2016. PP.11-14.

13. Sokolov N.S. Methods of increasing the carrying capacity of reinforcement drilling injection piles // Proceedings of the 3rd All-Russian (9th International) conference "New in Architecture, Design Construction and Renovation NADCR-2016) -2016. Cheboksary: Chuvash State University Publishing House. PP. 304-316.

14. Sokolov N.S. Technological approaches of instalment of drilling injection piles with multiple enlargements // Residential construction. No 10. -2016. PP $54-59$.

15. Sokolov N.S., Sokolov S. N., Sokolov A. N. On the erroneous method of instalment of drilling injection piles using electric discharge technology// Residential construction. No 11. -2016. PP.20-29.

16. Sokolov N.S., Sokolov S. N., Sokolov A. N. Experience of using drilling injection piles EDT when mitigating emergency situations in a public building // Residential construction. No 12. -2016. PP.1-6.

17. Sokolov N.S., Nikoforova N.S., Sokolov S. N., Sokolov A. N. Use of drilling piles -ERT when mitigating pre-emergency situations when building foundations // Geotechnics. -2016. No5. PP.54-60.

Paper submitted: 03.08.2017.

Paper accepted: 02.11.2017.

This is an open access article distributed under the CC BY-NC-ND 4.0 terms and conditions. 